\title{
Eleventh Conference of Arab Red Crescent and Red Cross Societies
}

The Eleventh Conference of Arab Red Crescent and Red Cross Societies was held at Mogadishu from 2 to 6 July 1979. The Conference was hosted by the Somali Red Crescent and was attended by representatives of Arab National Societies of North African and Middle East countries and by the secretariat general of Arab Red Crescent and Red Cross Societies led by its Secretary General, Mr. A. M. Ashi. The delegation of the League of Red Cross Societies was headed by Mr. H. Beer, its Secretary General, and that of the ICRC by Mr. J. Moreillon, Director of the Department of Principles and Law. The Henry Dunant Institute was represented by Mr. P. Gaillard.

Mr. A. M. Ashi delivered the opening address, after which the Conference listened with attention to the ICRC's report on its activities. Next, it examined the question of the development and reinforcement of existing National Societies and the aid they might be capable of furnishing to emerging and still unrecognized societies in Arab countries: in the Yemen Arab Republic, the People's Democratic Republic of Yemen, the United Arab Emirates, Oman, Djibouti and Qatar. It was suggested that each of these emerging societies should be "sponsored " by a recognized National Society, which would, by maintaining direct and steady contact with it, provide efficacious aid.

The problems connected with the dissemination of international humanitarian law and with the seminars organized in Arab and African countries (in Mombasa, Tunis and Amman) on this subject were carefully examined by the participants in the Conference, who all recognized the importance of imparting knowledge of this law not only to government, university and military sectors, but also to the public at large.

It was decided that the next Conference of Arab Red Crescent and Red Cross Societies would be held in Khartoum. 